\title{
BENEFICIOS A AUTORES DE DELITOS DE LESA HUMANIDAD EN ARGENTINA: LA CORTE SUPREMA DE JUSTICIA Y UN POLÉMICO FALLO
}

\author{
Isaac Marcelo BASAURe MiRANDA \\ Abogado por la Universidad Nacional \\ de Lomas de Zamora (Argentina) \\ Diplomado en Derechos Económicos, Sociales \\ y Culturales por la Universidad Nacional \\ de la Patagonia San Juan Bosco (Argentina) \\ isaacbasaure@gmail.com
}

\begin{abstract}
RESUMEN
El objetivo del presente artículo consiste en determinar si la reciente sentencia de la Corte Suprema de Justicia de la Nación Argentina respeta o no el ordenamiento jurídico interno e internacional relativo a los delitos de lesa humanidad. En el fallo caratulado Bignone, Reynaldo Benito Antonio y otro vs. recurso extraordinario, emitido el 3 de mayo de 2017, la Corte Suprema resolvió beneficiar al señor Luis Muiña, condenado por crímenes de lesa bumanidad, ordenando que se aplique en su caso la Ley 24.390, comúnmente conocida como «Ley del 2x1». La misma establece que, una vez transcurridos los dos primeros años de prisión preventiva, se computarán dos días de prisión por cada día de encarcelamiento cautelar efectivamente cumplido. En este trabajo se buscará entonces determinar si el otorgamiento de tal beneficio supone una violación a la legislación pertinente.
\end{abstract}

Palabras clave: Corte Suprema de Justicia Argentina, delitos de lesa humanidad, derechos humanos, Dos por Uno.

\section{ABSTRACT}

The aim of this article is to establish whether the recent sentence by the Supreme Court of Justice of Argentina is respectful of the National and International Legal Systems regarding crimes against Humanity. In the sentence sleeved as Bignone, Reynaldo Benito Antonio and other vs. extraordinary resource of 3 May 2017, the Supreme Court decided its verdict in favour of Mr Luis Muiña, convicted of Crimes against Humanity, disposing that the law that applied was Act 24.390, colloquially known as «2x1 Act». Such law establishes that, once the first two years of preventive prison have timed up the account will go as follows: two days of prison per day of preventive prison effectively served in prison. Through this piece of work we will then try to establish whether such benefit toward the convicted person implies a breach of the law which applies here.

Keywords: Argentinian Supreme Court of Justice, Crimes against Humanity, Human Rights, Two Times One. 
Isaac Marcelo Basaure Miranda Beneficios a autores de delitos de lesa bumanidad...

\section{ZUSSAMENFASSUNG}

Das Ziel des vorliegenden Aufsatzes ist es, festzustellen, ob das kürzlich ergangene Gerichtsurteil des obersten Gerichtshofs von Argentinien die interne und internationale Rechtsordnung bezüglich von Verbrechen gegen die Menschlichkeit beachtet oder nicht. Im Urteil unter der Bezeichnung Bignone, Reynaldo Benito Antonio y otro vs. recurso extraordinario ergangen am 3. Mai 2017, entschied der Oberste Gerichtshof, auf Herrn Luis Muiña, verurteilt wegen Verbrechen an der Menschlichkeit, das Gesetz 24.390 anzuwenden, das auch als das „zwei-für-eins-Gesetz" bekannt ist. Das Gesetz sieht vor, dass nach den ersten beiden Gefängnisjabren, für jeden in Vorbeugehaft verbüßtenTag, zwei Gefängnistage berechnet werden. In dieser vorliegenden Arbeit wird versucht zu bestimmen, ob die gewäbrte Vergünstigung eine Verletzung der anwendbaren Gesetzgebung darstellt.

Schlüsselwörter: oberster Gerichtshof von Argentinien, Verbrechen gegen die Menschlichkeit, Menschrechte, zwei-für-eins-Gesetz.

SUMARIO: I. INTRODUCCIÓN.-II. LA LEY PENAL MÁS BENIGNA: SU RECEPCIÓN EN LOS TRATADOS INTERNACIONALES Y SU INTERPRETACIÓN EN LA LEGISLACIÓN ARGENTINA.-III. EL CONGRESO DE LA NACIÓN SANCIONA UNA LEY PARA PROHIBIR LA APLICACIÓN DE LA LEY 24.390 A DELITOS DE LESA HUMANIDAD.-IV. EL BENEFICIO DEL DOS POR UNO OTORGADO POR LA CSJN Y SU CONTRADICCIÓN CON LA JURISPRUDENCIA DE LA CORTE INTERAMERICANA DE DERECHOS HUMANOS.-V. CONCLUSIÓN.-VI. BIBLIOGRAFÍA.

\section{INTRODUCCIÓN}

El objeto del presente trabajo es determinar si la Corte Suprema de Justicia de la Nación Argentina (en adelante, CSJN), en su reciente fallo titulado Bignone, Reynaldo Benito Antonio y otro vs. recurso extraordinario ${ }^{1}$, emitido el día 3 de mayo de 2017, ha incurrido en una violación de la normativa nacional y de los tratados internacionales de derechos humanos ratificados por Argentina. En la sentencia aludida, el máximo Tribunal de Justicia ordenó aplicar, por mayoría simple (votaron a favor Carlos Rosenkrantz, Elena Highton de Nolasco y Horacio Rosatti, mientras que los votos en disidencia correspondieron a Ricardo Luis Lorenzetti y Juan Carlos Maqueda),

${ }^{1}$ CSJN, «Bignone, Reynaldo Benito Antonio y otro vs. recurso extraordinario», Sentencia de 3 de mayo de 2017, fallos 340:549, disponible en bttp://www.csin.gov.ar y bttp://sjconsulta. csjn.gov.ar/sjconsulta/documentos/verDocumentoByIdLinksJSP.html? idDocumento=7373073 (consulta: 18 de septiembre de 2017). 
el art. $7 .^{\circ 2}$ de la Ley $24.390^{3}$ —promulgada el 21 de noviembre de 1994 y derogada el 30 de mayo de 2001 por la Ley $25.430^{4}$ - , conocida popularmente bajo el nombre de «Ley del 2x1». Dicha designación se explica por el hecho de que el artículo precitado establece que, una vez que la prisión preventiva ha superado el plazo de dos años, se computará por un día de prisión preventiva, dos de prisión o uno de reclusión. En el fallo en cuestión, la CSJN, basándose en la aplicación del principio de la ley penal más benigna — art. 2. ${ }^{\circ}$ del Código Penal argentino ${ }^{5}$-, otorgó este beneficio al señor Luis Muiña, condenado por el Tribunal Oral en lo Criminal Federal núm. 2 a la pena de trece años de prisión por la comisión de delitos calificados como de lesa humanidad ${ }^{6}$. Este tribunal de primera instancia utilizó para el cómputo de detención y pena el art. $7 .^{\circ}$ de la Ley 24.390; sin embargo, contra tal decisión el Ministerio Público Fiscal (en adelante, MPF) dedujo recurso de casación al considerar que el art. 2. ${ }^{\circ}$ del Código Penal no resultaba de aplicación al caso, ya que el derecho al tratamiento más benigno tiene como único fundamento la existencia de alguna modificación en la valoración que la comunidad realiza respecto de la clase de delitos que configuran los hechos por los que fue condenado Luis Muiña. Más tarde, el 28 de marzo de 2014, la Sala IV de la Cámara Federal de Casación Penal ${ }^{7}$, acogiendo el reclamo del MPF, dispuso anular el cómputo punitivo resuelto por el tribunal y ordenó aplicar uno nuevo, con la prescindencia del bene-

2 Art. 7. ${ }^{\circ}$ de la Ley 24.390: «Transcurrido el plazo de dos años previsto en el art. 1 se computará por un día de prisión preventiva dos de prisión o uno de reclusión».

3 Congreso de la Nación, Ley 24.390, Buenos Aires, 21 de noviembre de 1994, disponible en http://servicios.infoleg.gob.ar/infolegInternet/anexos/0-4999/776/norma.htm (consulta: 18 de septiembre de 2017).

${ }^{4}$ Congreso de la Nación, Ley 25.430, Buenos Aires, 30 de mayo de 2001, disponible en http://servicios.infoleg.gob.ar/infolegInternet/anexos/65000-69999/67171/norma.htm (consulta: 18 de septiembre de 2017).

5 Art. 2. ${ }^{\circ}$ del Código Penal de la Nación Argentina: «Si la ley vigente al tiempo de cometerse el delito fuere distinta de la que exista al pronunciarse el fallo o en el tiempo intermedio, se aplicará siempre la más benigna». Vid. http://servicios.infoleg.gob.ar/infolegInternet/anexos/15000-19999/16546/texact.htm (consulta: 18 de septiembre de 2017).

${ }^{6}$ Tribunal Oral en lo Criminal Federal núm. 2, «Bignone, Reynaldo Benito Antonio; Muiña, Luis, y Mariani, Hipólito Rafael s/inf. arts. 144 bis, inciso $10^{\circ}$ y último párrafo -Ley 14.616-; 142, incisos $10^{\circ}$ y $5 .^{\circ}$ - Ley 20.642- del CP», Sentencia del 29 de diciembre de 2011, causa núm. 1696, disponible en http://www.cij.gov.ar/ y bttp://www.cij.gov.ar/ nota-8497-Derechos-bumanos--condenaron-a-Bignone-a-15-anos-de-prision-por-crimenescometidos-en-el-Hospital-Posadas.html (consulta: 18 de septiembre de 2017).

${ }^{7}$ Cámara Federal de Casación Penal, Sala IV, «Bignone, Reynaldo Benito A. y otro vs. recurso de casación», Sentencia de 28 de marzo de 2014, causa núm. 1731/2013, disponible en bttp://www.fiscales.gob.ar/y bttp://www.fiscales.gob.ar/wp-content/uploads/2014/05/fallocasaci\%C3\%B3n-2x1-Bignone-Mui\%C3\%B1a.pdf. (consulta: 18 de septiembre de 2017). 
ficio contemplado en la Ley 24.390. Finalmente, la defensa oficial ad boc del imputado, Magdalena Laiño, interpuso recurso extraordinario federal ante la Cámara, el cual fue denegado, lo que motivó el posterior recurso de queja ante la CSJN, la cual hizo lugar a la queja, declaró admisible el recurso extraordinario y ordenó dejar sin efecto la sentencia apelada.

El fallo de la CSJN suscitó una intensa consternación en la sociedad argentina, cuya memoria e imaginario social aún se conmueven al recordar a los más de 30.000 desaparecidos —la Ley 14.910 de la Provincia de Buenos Aires ${ }^{8}$, promulgada el 12 de mayo de 2017, ha contribuido a zanjar las controversias acerca del número real de desaparecidos al ordenar se incorpore en todas las publicaciones y actos de gobierno de la provincia el número 30.000 junto a la expresión «desaparecidos»— que provocó la última dictadura cívico-militar argentina (1976-1983). Dicho malestar social se materializó en una masiva marcha ${ }^{9}$ para repudiar la sentencia que tuvo lugar el 10 de mayo de 2017 ante el Palacio de Justicia de la Nación (sede de la CSJN). En el acto participaron diferentes organismos de derechos humanos tales como: las Abuelas de Plaza de Mayo, Madres de Plaza de Mayo, Familiares de Desaparecidos y Detenidos por Razones Políticas, entre otros. Paralelamente, mientras se convocaba la protesta, el Congreso de la Nación comenzó a gestar un proyecto legislativo con el fin de evitar que el beneficio del dos por uno pueda ser potencialmente aplicado a otras causas del mismo tenor. Así, el 10 de mayo de 2017 se sancionó la Ley $27.362^{10}$, que declaró la inaplicabilidad de la Ley 24.390 a delitos de lesa humanidad. Al día siguiente, el 11 de mayo, la ley fue promulgada por el poder ejecutivo nacional —encabezado por el ingeniero Mauricio Macri- a través del Decreto 329/2017 ${ }^{11}$.

En el plano internacional, la sentencia de la CSJN ha sufrido severas críticas, generando preocupación en los principales organismos de protección de derechos humanos. En este sentido debemos mencionar el comu-

${ }^{8}$ Cámara de Diputados de la Provincia de Buenos Aires, Ley 14.910, Provincia de Buenos Aires, 12 de mayo de 2017, disponible en https://www.hcdiputados-ba.gov.ar/includes/ ley_completa.php? vnroley=14910 (consulta: 18 de septiembre de 2017).

9 G. BRaslavsKY, «Masiva marcha a Plaza de Mayo en repudio del fallo del 2x1 para los represores», Diario Clarín, 2017, disponible en https://www.clarin.com/politica/masiva-marchaplaza-mayo-repudiar-fallo-represores_0_rkTThNWeW.html (consulta: 18 de septiembre de 2017).

${ }^{10}$ Congreso de la Nación, Ley 27.362, Buenos Aires, 10 de mayo de 2017, disponible en http://servicios.infoleg.gob.ar/infolegInternet/anexos/270000-274999/274607/norma.htm (consulta: 18 de septiembre de 2017).

${ }^{11}$ Poder Ejecutivo Nacional, Decreto 329/2017, Buenos Aires, 11 de mayo de 2017, disponible en bttp://servicios.infoleg.gob.ar/infolegInternet/anexos/270000-274999/274608/ norma.htm (consulta: 18 de septiembre de 2017). 
nicado de prensa ${ }^{12}$ de la Comisión Interamericana de Derechos Humanos (en adelante, CIDH) de 15 de mayo de 2017, al sostener que la decisión de la CSJN «se aparta de los estándares internacionales en la persecución de graves violaciones a los derechos humanos» ${ }^{12}$. En consonancia con la CIDH, la Oficina del Alto Comisionado para los Derechos Humanos (en adelante, ACNUDH) de la Organización de las Naciones Unidas (en adelante, $\mathrm{ONU}$ ) envió un comunicado ${ }^{13}$ dirigido al Gobierno argentino, fechado el 15 de junio de 2017, en el que expresa su preocupación por las implicancias del fallo.

Presentados, a modo introductorio, los principales antecedentes y derivaciones de la sentencia, examinaremos, teniendo como marco conceptual la Constitución Nacional argentina (en adelante, $\mathrm{CN}$ ) y los tratados internacionales por ella incorporados, si la CSJN, al valerse de la ley penal más benigna para beneficiar a un imputado por delitos de lesa humanidad, ha violentado los preceptos del Derecho interno e internacional relativos a los derechos humanos aplicables al caso.

\section{LA LEY PENAL MÁS BENIGNA: SU RECEPCIÓN EN LOS TRATADOS INTERNACIONALES Y SU INTERPRETACIÓN EN LA LEGISLACIÓN ARGENTINA}

Uno de los principales argumentos que esgrimió la CSJN en el fallo Bignone, Reynaldo Benito Antonio y otro vs. recurso extraordinario para otorgar el beneficio de la Ley 24.390 a Luis Muiña fue la interpretación que realizó del principio de la ley penal más benigna receptado en el art. 2. ${ }^{\circ}$ del Código Penal, el cual establece que: «Si la ley vigente al tiempo de cometerse el delito fuere distinta de la que exista al pronunciarse el fallo o en el tiempo intermedio, se aplicará siempre la más benigna». Muiña fue condenado a trece años de prisión por el Tribunal Oral en lo Criminal núm. 2, en su Sentencia de 29 de diciembre de 2011; en ella se lo consideró coautor penalmente responsable del delito de privación ilegal

${ }_{12}$ Comisión Interamericana de Derechos Humanos, Comunicado de prensa núm. 060/17, 15 de mayo de 2017, Washington DC, disponible en http://www.oas.org/es/ cidh/prensa/comunicados/2017/060.asp (consulta: 18 de septiembre de 2017).

13 Organización de Naciones Unidas (ONU), Oficina del Alto Comisionado para los Derechos Humanos (ACNUDH), Comunicado oficial, 17 de junio de 2017, Ginebra, Suiza, disponible en http://www.ohchr.org/Documents/Issues/Truth/ComunicacionConjuntafromSP_Ley2x1Argentina.pdf (consulta: 18 de septiembre de 2017). 
de la libertad cometido por funcionario público con abuso de sus funciones, agravado por el uso de violencia o amenazas, en concurso ideal con el delito de imposición de tormentos en relación con las condiciones de cautiverio impuestas y en concurso real con el delito de imposición de tormentos impuestos por un funcionario público al preso que guarde. Estos delitos se comprobaron en cinco oportunidades, en perjuicio de Gladis Evarista, Jacobo Chester, Jorge Mario Roitman, Jacqueline Romano y Marta Elena Graiff. Tanto Chester como Roitman fueron víctimas de desaparición forzada de personas ${ }^{14}$.

Los hechos que se le imputaron a Muiña tuvieron lugar en el hospital Posadas —ubicado en el Partido de Morón, Gran Buenos Aires-y sus víctimas fueron personal del citado nosocomio. Ahora bien, la fecha en que se comenzaron a perpetrar esta serie de delitos fue el 28 de marzo de 1976, es decir, dos días después de ocurrido el golpe de Estado. De modo que las leyes vigentes al tiempo de cometerse el delito fueron la Ley 20.642 y la Ley 14.616, ambas correspondientes al Código Penal y al Código Procesal Penal de la Nación. Como se ha dicho, la sentencia de primera instancia data del año 2011, por lo que en el lapso de tiempo transcurrido entre 1976 (fecha de comisión del delito) y 2011 (fecha en que se pronunció el fallo) se produjo la sanción de la Ley 24.390, concretamente en el año 1994. La CSJN entendió que la aparición de la Ley 24.390 entraba en el supuesto contemplado por el art. 2. ${ }^{\circ}$ del Código Penal; por lo mismo, ordenó que el cómputo de la pena dictada a Luis Muiña fuera hecho de acuerdo a la normativa más benigna. En este punto debemos señalar que el art. 3. ${ }^{\circ}$ del Código Penal dispone que: «En el cómputo de la prisión preventiva se observará separadamente la ley más favorable al procesado» ${ }^{15}$. Sin embargo, lo que la CSJN no tuvo en cuenta fue que la Ley 24.390 se derogó en el año 2001, de modo que sus disposiciones jamás podrían alterar una sentencia que ocurrió diez años después (2011). El principio de la ley penal más benigna se halla expresamente reconocido en la Convención Americana sobre Derechos Humanos (en adelante, $\mathrm{CADH}$ ), puesto que en su art. 9. ${ }^{\circ}$ establece que: «Si con posterioridad a la comisión del delito

${ }^{14}$ Ministerio de Justicia y Derechos Humanos de la Nación Argentina, Registro Unificado del Terrorismo de Estado (RUVTE), «Listado de víctimas del accionar represivo ilegal», 30 de septiembre de 2016, disponible en http://datos.jus.gob.ar/dataset/registro-unificado-devictimas-del-terrorismo-de-estado-ruvte (consulta: 18 de septiembre de 2017).

${ }_{15}$ Código Penal de la Nación Argentina, Ley 11.179, disponible en http://servicios.infoleg.gob.ar/infolegInternet/anexos/15000-19999/16546/texact.htm\#2 (consulta: 19 de septiembre de 2017). 
la ley dispone la imposición de una pena más leve, el delincuente se beneficiará de ello» ${ }^{16}$.

Idéntica postura adopta el art. 15.1 del Pacto Internacional de Derechos Civiles y Políticos ${ }^{17}$ (en adelante, PIDCP). Más recientemente (1998) fue incluido en el Estatuto de Roma (en adelante, ER), en su art. 24.2: «De modificarse el Derecho aplicable a una causa antes de que se dicte la sentencia definitiva, se aplicarán las disposiciones más favorables a la persona objeto de la investigación, el enjuiciamiento o la condena» ${ }^{18}$. La CADH fue aprobada por Argentina mediante Ley $23.054^{19}$, la cual fue promulgada por el Congreso de la Nación el 19 de marzo de 1984; el PIDCP, por su parte, fue aprobado por el Estado argentino a través de la Ley 23.31320, promulgada el 6 de mayo de 1986; por último, el ER se incorporó en la legislación argentina mediante Ley $26.200^{21}$, promulgada el 5 de enero de 2007. Dichos instrumentos internacionales se integraron al ordenamiento jurídico argentino tras su aprobación, y según el art. 75 , inciso 22, de la $\mathrm{CN}$, gozan de jerarquía constitucional, por lo que detentan el mismo rango de importancia que la misma $\mathrm{CN}^{22}$.

La CSJN, en el caso Muiña, entendió que, de no aplicar la ley penal más benigna —en este caso la 24.390—, se estarían violentando las garantías y principios fundamentales de la normativa interna y constitucional. El

${ }^{16}$ Convención Americana sobre Derechos Humanos (Pacto de San José), San José, Costa Rica, 22 de noviembre de 1969, disponible en https://www.oas.org/dil/esp/tratados_b-32_ convencion_americana_sobre_derechos_bumanos.htm (consulta: 19 de septiembre de 2017).

17 Art. 15.1 del Pacto Internacional de Derechos Civiles y Políticos (PIDCP): «Si con posterioridad a la comisión del delito la ley dispone la imposición de una pena más leve, el delincuente se beneficiará de ello». Vid. http://www.obchr.org/SP/ProfessionalInterest/ Pages/CCPR.aspx (consulta: 19 de septiembre de 2017).

${ }^{18}$ Estatuto de Roma de la Corte Penal Internacional, Roma, Italia, 17 de julio de 1998, disponible en http://www.acnur.org/fileadmin/scripts/doc.php?file=fileadmin/Documentos/ BDL/2002/0033 (consulta: 19 de septiembre de 2017).

19 Congreso de la Nación, Ley 23.054, Buenos Aires, 19 de mayo de 1984, disponible en bttp://servicios.infoleg.gob.ar/infolegInternet/anexos/25000-29999/28152/norma.htm (consulta: 19 de septiembre de 2017).

${ }^{20}$ Congreso de la Nación, Ley 23.313, Buenos Aires, 6 de mayo de 1986, disponible en http://servicios.infoleg.gob.ar/infolegInternet/anexos/20000-24999/23782/norma.htm (consulta: 19 de septiembre de 2017).

${ }^{21}$ Congreso de la Nación, Ley 26.200, Buenos Aires, 5 de enero de 2007, disponible en http://servicios.infoleg.gob.ar/infolegInternet/anexos/120000-124999/123921/norma.htm (consulta: 19 de septiembre de 2017).

22 Art. 75, inciso 22, de la Constitución Nacional argentina: «En las condiciones de su vigencia tienen jerarquía constitucional, no derogan artículo alguno de la primera parte de esta Constitución y deben entenderse complementarios de los derechos y garantías por ella reconocidos». Vid. http://servicios.infoleg.gob.ar/infolegInternet/anexos/0-4999/804/norma. btm (consulta: 19 de septiembre de 2017). 
fallo sostiene: «Un Estado de Derecho no es aquel que combate a la barbarie apartándose del ordenamiento jurídico, sino respetando los derechos y garantías que han sido establecidos para todos, aun para los condenados por delitos aberrantes». Además, en su considerando $7 .^{\circ}$, segundo párrafo, afirma que: «El uso del adverbio "siempre" en el texto del art. $2 .^{\circ}$ del Código Penal da cuenta de la clara decisión del legislador respecto de la aplicabilidad universal del principio de la ley más benigna».

La CSJN realiza una exégesis jurídica textual del articulado. La interpretación literal de una norma conlleva el riesgo de erosionar el sentido de justicia y reduce a los intérpretes del Derecho a ser unos meros autómatas que, burocráticamente, aplican la ley, obviando la importancia que debe reconocerse al contexto y al espíritu sistémico que late dentro de los derechos legislados. Con este razonamiento, la CSJN efectúa una interpretación sesgada tanto de la misión con la que fue sancionada la Ley 24.390 como de la legislación nacional y extranjera. En primer término, la mentada ley del dos por uno no surgió como el resultado de un cambio en la reprobación social respecto de los delitos considerados como de lesa humanidad, sino que fue concebida como un mecanismo destinado a limitar temporalmente los encierros preventivos para contenerlos dentro de los plazos razonables exigidos por el art. 7.5 $\mathrm{CADH}^{23}$. Por lo que la decisión de aplicar la ley penal más benigna en su modalidad ultra activa — supervivencia de la ley más allá de su periodo de existencia, más allá de su derogación $-{ }^{24}$ resulta errónea, debido a que no se han configurado los postulados que autorizan tal retroactividad. El presupuesto esencial para que opere es que la sanción de la norma más benigna, es decir, la ley posterior al hecho, implique efectivamente un cambio en la valoración del delito en cuestión por parte de la sociedad y del legislador. Tal es lo que estipula la jurisprudencia de la CSJN: «El derecho del imputado a beneficiarse por una nueva configuración normativa es, en principio, comprensivo de los supuestos en que la norma modificada, aunque ajena al derecho represivo, condiciona la sanción penal. Pero la modificación de tales preceptos

${ }^{23}$ Art. 7.5 de la Convención Americana sobre Derechos Humanos (Pacto de San José): «Toda persona detenida o retenida debe ser llevada, sin demora, ante un juez u otro funcionario autorizado por la ley para ejercer funciones judiciales y tendrá derecho a ser juzgada dentro de un plazo razonable o a ser puesta en libertad, sin perjuicio de que continúe el proceso. Su libertad podrá estar condicionada a garantías que aseguren su comparecencia en el juicio».Vid. https://www.oas.org/dil/esp/tratados_b-32_convencion_americana_sobre_derechos_bumanos.htm (consulta: 19 de septiembre de 2017).

${ }^{24}$ J. Clariá Olmedo, Derecho Procesal Penal, vol. I, Córdoba, Rubinzal-Culzoni, 1984, pp. 104-105. 
no configura un régimen más benigno si no traduce un criterio legislativo de mayor lenidad en orden a la infracción cometida» ${ }^{25}$.

Los hechos imputados a Luis Muiña no sólo continúan siendo delitos en Argentina, sino que además no se ha registrado una alteración en la valoración social ni legislativa respecto a la reprobación de los delitos de lesa humanidad. Al respecto, el presidente de la CSJN, Ricardo Luis Lorenzetti, expresa en su voto en disidencia (considerando $7 .^{\circ}$ ) que: «Existe una consistencia en la definición, calificación y persecución de este tipo de delitos que se ha mantenido en diversos precedentes no sólo de esta Corte Suprema, sino de todo el poder judicial». Luego afirma que la persecución de los delitos de lesa humanidad en Argentina representa «una política de Estado afirmada por los tres poderes en diversas épocas, de modo que constituye parte del contrato social de los argentinos».

No es posible eludir que el beneficio otorgado por la CSJN a Luis Muiña proviene de una ley derogada. El sistema dispuesto por la Ley 24.390 no dio resultado, por lo que el cómputo fue derogado por Ley 25.430. Aplicar una ley derogada acarrea el peligro de desconocer la voluntad del legislador y, por tanto, de la ciudadanía a la que éstos representan. En este sentido es oportuno identificar los fundamentos por los cuales el Congreso de la Nación derogó la ley del dos por uno. Primeramente debemos comenzar analizando el Diario de Sesiones de la Cámara de Diputados correspondiente a la 3. ${ }^{a}$ reunión, 1. ${ }^{a}$ sesión ordinaria, del 14 de marzo del 2001, en el que se aprobó un dictamen único, por consenso, por el que se estableció modificar la Ley 24.390 sobre plazos para la prisión preventiva. Al respecto, el diputado Miguel Ángel Pichetto, miembro de la Comisión de Legislación Penal del Congreso, expuso: «Quiero destacar la importancia de este debate y del consenso logrado en la tarde de ayer, en línea con un pensamiento que está fuertemente arraigado en la sociedad y que hacía necesario que el Congreso derogara una norma que realmente significa un beneficio o premio para el delincuente» ${ }^{26}$. Con esta afirmación, el diputado da cuenta del rechazo que ha generado en la sociedad argentina la aplicación del dos por uno. Más adelante, en otro de sus

${ }^{25}$ CSJN, «Vigil, Constancio y otros vs. contrabando», Sentencia de 9 de noviembre de 2000, fallos 323:3426, disponible en bttp://www.csjn.gov.ar y http://sjconsulta.csjn. gov.ar/sjconsulta/documentos/verUnicoDocumentoLink. html? idAnalisis $=494138$ Ecache $=$ 1505940475397 (consulta: 20 de septiembre de 2017).

26 Sesiones de la Cámara de Diputados de la Nación, 3. a reunión, 1. a sesión ordina-

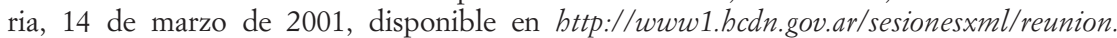
asp? $p=119 \varepsilon r=3$ (consulta: 21 de septiembre de 2017). 
pasajes, nos ofrece un aporte sustancial para el caso en estudio: «La eliminación del dos por uno no resuelve el problema de la inseguridad ciudadana, pero creo que encierra una gran simbología. Pienso que la derogación de esta ley es un gran mensaje que emite la Cámara de Diputados, un mensaje acorde con el pensamiento ciudadano y que además va a evitar distorsiones y hechos graves como los que hemos vivido con los sucesivos casos en los que reincidentes beneficiados por el dos por uno cometieron delitos aberrantes ${ }^{26}$. La exposición del diputado Pichetto permite entrever el fracaso de la Ley 24.390 al producirse una desviación en su finalidad, es decir, fue concebida para producir una mejora en la administración de justicia, para lograr que la persona detenida sea llevada sin demoras ante un juez a los fines de que éste decida sobre su situación legal. Se buscó evitar que la prisión preventiva se prolongue indefinidamente y que el detenido quede confinado en una suerte de limbo jurídico a la espera de ser juzgado. Sin embargo, pese a esa intención, los resultados de la puesta en funcionamiento de la ley fueron negativos debido a que delincuentes que cometieron graves delitos recuperaban rápidamente su libertad al cumplir un día de condena como si fuesen dos.

Aquí se debe destacar la participación que tuvo el procurador general de la Suprema Corte de Justicia de la Provincia de Buenos Aires, Eduardo Matías de la Cruz, quien en el año 2000 solicitó la anulación del dos por uno luego de conocer un informe efectuado sobre la base de datos del Servicio Penitenciario Bonaerense, el cual reveló que entre 1994 (fecha en que se promulgó la Ley 24.390) y el año 2000 más de 15.000 delincuentes detenidos en presidios de máxima seguridad de la provincia de Buenos Aires obtuvieron su libertad sin haber llegado a cumplir el total de su condena ${ }^{27}$. Después de que la Cámara de Diputados sancionara el proyecto de derogación, el mismo pasó al Senado, donde fue aprobado por unanimidad, según consta en el Diario de Sesiones de la Cámara de Senadores, en su 24. ${ }^{a}$ reunión, 6. ${ }^{a}$ sesión ordinaria, del 3 de mayo de 2001; en ella, el principal orador fue el senador de la Unión Cívica Radical por la provincia de San Luis, Jorge Alfredo Agúndez, quien resumió la problemática al declarar que: «En 1994 el objetivo fue establecer un tiempo a la prisión preventiva. Pero luego de sucesivas modificaciones y tanto tratamiento se terminó por incorporar el "dos por uno". En consecuencia, se desvirtuó el

${ }^{27}$ L. Moreiro, «Proponen derogar el beneficio del 2x1», Diario La Nación, 2000, disponible en bttp://www.lanacion.com.ar/22963-proponen-derogar-el-beneficio-del-2-x-1 (consulta: 21 de septiembre de 2017). 
problema fundamental, que era el tiempo de prisión preventiva, y con ello el cumplimiento de los términos del Pacto de San José de Costa Rica» ${ }^{28}$. Como se ha expuesto, el Congreso Nacional manifestó su enérgico rechazo a las consecuencias nefastas del dos por uno en la realidad criminal argentina, lo cual refuerza la importancia de su derogación, ya que, precisamente al adquirir la norma tal característica — la de no estar más en vigencia-, los otros poderes del Estado, en especial el poder judicial, deben abstenerse de emplearla, máxime en el caso de delitos de lesa humanidad.

La CSJN en el fallo Bignone, Reynaldo Benito Antonio y otro vs. recurso extraordinario no sólo avasalló la voluntad del legislador al hacer uso de una ley derogada, sino que al aplicar la Ley 24.390 valiéndose del principio de ley penal más benigna violó la Ley 27.156 promulgada por el Estado argentino el 24 de julio de 2015, la cual dispone en su art. $1 .^{\circ}$ la prohibición de conmutar penas a delitos de lesa humanidad: «Las penas o procesos penales sobre los delitos de genocidio, de lesa humanidad y crímenes de guerra contemplados en los arts. 6. ${ }^{\circ}, 7 .^{\circ}$ y $8 .^{\circ}$ del Estatuto de Roma de la Corte Penal Internacional y en los tratados internacionales de derechos humanos con jerarquía constitucional no pueden ser objeto de amnistía, indulto o conmutación de pena, bajo sanción de nulidad absoluta e insanable del acto que lo disponga» ${ }^{29}$. Los supuestos que prevé el articulado están comprobados en el fallo en análisis, ya que la CSJN efectuó una clara conmutación de la pena a un condenado - Luis Muiña — por delitos de lesa humanidad. Se debe agregar, además, que el Tribunal Oral en lo Criminal Federal núm. 2 que condenó a Muiña calificó «los hechos objeto de este proceso como constitutivos de crímenes de lesa humanidad».

En este punto debemos preguntarnos ¿qué constituye un crimen de lesa humanidad? El ER brinda respuesta a dicho interrogante, ya que su art. 7. afirma: «Se entenderá por "crimen de lesa humanidad" cualquiera de los actos siguientes cuando se cometa como parte de un ataque generalizado o sistemático contra una población civil y con conocimiento de dicho ataque» ${ }^{18}$. Los actos que menciona el ER son numerosos, pero entre ellos figuran los que ha cometido Luis Muiña, tales como asesinato, tortura, desaparición forzada de personas, privación grave de la libertad física y

${ }^{28}$ Sesiones de la Cámara de Senadores de la Nación, 24. ${ }^{a}$ reunión, 6. ${ }^{a}$ sesión ordinaria, 3 de mayo de 2001, disponible en http://www.senado.gob.ar/ y bttp://www.senado.gob.ar/ parlamentario/sesiones/busqueda. (consulta: 21 de septiembre de 2017).

${ }_{29}$ Congreso de la Nación, Ley 27.156, Buenos Aires, 24 de julio de 2015, disponible en http://servicios.infoleg.gob.ar/infolegInternet/anexos/245000-249999/249820/norma.htm (consulta: 21 de septiembre de 2017). 
la persecución de un grupo fundada en motivos políticos. Por lo expuesto, queda fundada la negativa del Estado argentino a incluir a los delitos de lesa humanidad dentro de la categoría de amnistiables y conmutables; por el contrario, los entiende como delitos imprescriptibles, sobre los cuales no puede recaer ningún tipo de condonación de pena.

\section{EL CONGRESO DE LA NACIÓN SANCIONA UNA LEY PARA PROHIBIR LA APLICACIÓN DE LA LEY 24.390 A DELITOS DE LESA HUMANIDAD}

Como consecuencia del fallo de la CSJN, el Congreso Nacional sancionó el 10 de mayo de 2017 — tan sólo una semana después de emitida la sentencia- la Ley 27.362. En ella, los legisladores dictaminaron que el art. $7 .^{\circ}$ de la Ley 24.390 no es aplicable a conductas delictivas que se encuadren dentro de la categoría de delitos de lesa humanidad, genocidio o crímenes de guerra, según el Derecho interno o internacional ${ }^{10}$. Por otro lado, la intención de los congresistas fue establecer un límite a la aplicación de la ley penal más benigna en materia de delitos contra la humanidad, ya que en su art. 2. ${ }^{\circ}$ la norma dispone que el cómputo de las penas, resuelto en el art..$^{\circ}$ de la Ley 24.390, se aplicará exclusivamente en aquellos casos en que el condenado hubiere estado privado de la libertad en forma preventiva durante el lapso de tiempo comprendido entre la entrada en vigencia y la derogación de aquélla $\mathrm{a}^{10}$.

Un examen acerca del origen de esta nueva ley dictada por el Congreso fortalecerá el razonamiento de que la CSJN llevó a cabo una interpretación excesivamente literal de la Ley 24.390 y del art. 2. ${ }^{\circ}$ del Código Penal, ignorando la importancia que evoca para Argentina la persecución y condena efectiva de los delitos de lesa humanidad. Política de Estado que no sólo proviene de la normativa interna, sino también de las obligaciones internacionalmente asumidas en materia de derechos humanos por el Estado argentino.

La Ley 27.362 fue el resultado de un consenso político que aunó a todos los partidos que integran el Congreso; además, es dable destacar la celeridad que se le imprimió al tratamiento de una ley que limitase el beneficio otorgado por la CSJN. En la Cámara de Diputados fueron presentados una serie de proyectos de ley que proponían, en su mayoría, sancionar la inaplicabilidad de las disposiciones sobre prisión preventiva a los delitos de lesa humanidad, genocidio o crímenes de guerra. Otros, por el con- 
trario, enviaron proyectos de declaración en los que exigían rechazar en su totalidad el fallo, además de expresar su repudio. Finalmente, en la reunión 6. ${ }^{a}$ correspondiente a la 4. ${ }^{a}$ sesión ordinaria (especial) del 9 de mayo de $2017^{30}$, la Cámara de Diputados aprobó la Ley 27.362 con 211 votos a favor y uno en contra ${ }^{31}$.

De la lectura del Diario de Sesiones se puede discernir que la Cámara de Diputados se basó para la sanción de esta nueva norma en que la Ley 24.390 aún podría conservar efectos ultra activos, por lo que estimaron necesario determinar su alcance, específicamente, en relación a las responsabilidades del Estado argentino en materia de persecución penal de severas violaciones a los derechos humanos y, en particular, de crímenes de lesa humanidad. A pesar de que la Ley 24.390 no especifica en su texto original que los delitos de lesa humanidad no podrán ser objeto de su aplicación, dicha negativa surge al analizarse el contexto normativo en el cual se sancionó esta Ley. La misma fue promulgada en 1994, año en que en Argentina se encontraban vigentes la Ley 23.492, conocida como Ley de Punto Final ${ }^{32}$, sancionada el 24 de diciembre de 1986; la Ley 23.521, también llamada Ley de Obediencia Debida ${ }^{33}$, dictada el 4 de junio de 1987, y los indultos que el presidente Carlos Saúl Menem dispuso por medio de una constelación de decretos tales como: los Decretos 1002/89, 1003/89, 1004/89 y 1005/89, todos ellos correspondientes al año 1989, y los decretos 2741/90, 2742/90, $2743 / 90,2744 / 90,2745 / 90$ y 2746/90, pertenecientes al año $1990^{34}$. Las precitadas leyes e indultos establecían una serie de variados beneficios a una amplia cantidad de acusados por delitos de lesa humanidad cometidos durante la última dictadura cívico-militar argentina. Por tanto, eran inmu-

30 Sesiones de la Cámara de Diputados de la Nación, 6. ${ }^{a}$ reunión, 4. ${ }^{a}$ sesión ordinaria (especial), 9 de mayo de 2017, disponible en http://www.diputados.gov.ar/ (consulta: 21 de septiembre de 2017).

31 AgenCia TÉlAm, «Diputados aprobó el proyecto para bloquear cualquier reducción de penas a genocidas», 2017, disponible en bttp://www.telam.com.ar/ notas/201705/188390-diputados-aprueba-debatir-un-proyecto-contra-el-2x1.btml (consulta: 21 de septiembre de 2017).

32 Congreso de la Nación, Ley 23.492, Buenos Aires, 24 de diciembre de 1986, disponible en http://servicios.infoleg.gob.ar/infolegInternet/anexos/20000-24999/21864/norma.htm (consulta: 21 de septiembre de 2017).

33 Congreso de la Nación, Ley 23.521, Buenos Aires, 8 de junio de 1987, disponible en bttp://servicios.infoleg.gob.ar/infolegInternet/anexos/20000-24999/21746/norma.htm (consulta: 21 de septiembre de 2017).

34 F. Mignone, «Los decretos de indulto en la República Argentina», Revista IIDH, núm. 12 (1990) pp. 259-278, disponible en http://www.iidh.ed.cr/IIDH/media/1615/revistaiidh12.pdf (consulta: 21 de septiembre de 2017). 
nes al ejercicio de la acción penal y no podían ser perseguidos penalmente por haber sido beneficiados con indultos y leyes que respondían a la idea de obediencia debida y punto final; de modo que, normativamente, resultaba imposible que contra los autores de crímenes contra la humanidad se dictasen prisiones preventivas, lo cual era el objeto de la Ley 24.390. En síntesis, esta Ley no fue ideada para beneficiar a autores de crímenes de lesa humanidad, porque en el contexto temporal en el que fue sancionada éstos no eran pasibles de persecución penal. En otro sentido, se debe considerar la siguiente circunstancia: la Ley 24.390 se promulgó el 21 de noviembre de 1994, es decir, tres meses después de que se aprobase la última reforma constitucional argentina (22 de agosto de 1994) ${ }^{35}$ en la que se incorporaron tratados internacionales de derechos humanos que obligan al Estado argentino a perseguir y sancionar debidamente los delitos de lesa humanidad y las violaciones a los derechos humanos. La incompatibilidad entre la obligación internacionalmente asumida y la decisión de la CSJN al ordenar reducción de penas que desnaturalicen la gravedad de los delitos es clara y demuestra que el art. $7 .^{\circ}$ de la Ley 24.390 jamás estuvo dirigido a computar penas por delitos de lesa humanidad. Es claro, entonces, que la coyuntura jurídica en la que fue concebida la ley del dos por uno no guarda relación fáctica ni normativa con la interpretación incongruente ejecutada por la CSJN. En el mismo tenor se expresa el diputado Ricardo Alfonsín (hijo) durante su exposición en la sesión: «Este tipo de delitos no son los que fueron previstos en la ley del dos por uno. Ello es así porque los delitos que estamos juzgando en este caso eran no justiciables por la Ley de Obediencia Debida. De manera tal que cuando el legislador sancionó aquella ley (la Ley 24.390) no lo hizo pensando en esos delitos, que tenían que ver con el terrorismo de Estado» ${ }^{30}$. Una vez que la Cámara de Diputados dio media sanción al proyecto de ley, éste fue enviado para su tratamiento a la Cámara de Senadores. El Senado, en su 6. ${ }^{a}$ reunión, 4. ${ }^{a}$ sesión especial, del 10 de mayo de $2017^{36}$, votó por unanimidad ${ }^{37}$ ( 56 votos afirmativos, 0 negativos y 0 abstenciones) aprobar el proyecto para convertirlo en la Ley 27.362.

35 Diario de Sesiones de la Convención Nacional Constituyente, 35. reunión, 3. ${ }^{a}$ sesión ordinaria (continuación), 22 de agosto de 1994, disponible en bttp://www1.hcdn.gov.ar/ dependencias/dip/Debate-constituyente.htm (consulta: 21 de septiembre de 2017).

36 Sesiones de la Cámara de Senadores de la Nación, 6. ${ }^{a}$ reunión, 4. ${ }^{a}$ sesión especial, 10 de mayo de 2017, disponible en http://www.senado.gov.ar/ (consulta: 21 de septiembre de 2017).

37 «El Senado votó por unanimidad y es ley el límite al "dos por uno"», Diario La Nación, 2017, disponible en bttp://www.lanacion.com.ar/2022574-el-senado-voto-por-unanimidad-y-es-ley-el-limite-al-dos-por-uno (consulta: 21 de septiembre de 2017). 


\section{EL BENEFICIO DEL DOS POR UNO OTORGADO POR LA CSJN Y SU CONTRADICCIÓN CON LA JURISPRUDENCIA DE LA CORTE INTERAMERICANA DE DERECHOS HUMANOS}

A pesar de que la CSJN en el considerando $13 .^{\circ}$ del fallo Bignone, Reynaldo Benito Antonio y otro vs. recurso extraordinario afirma que la Corte Interamericana de Derechos Humanos (en adelante, Corte IDH) no se ha pronunciado de manera puntual sobre la aplicación de la ley penal más benigna a delitos permanentes, lo cierto es que sí existe un antecedente en el cual la Corte IDH se ha manifestado claramente en relación a esta temática. En su Sentencia de 11 de mayo de 2007, correspondiente al caso de la Masacre de La Rochela vs. Colombia ${ }^{38}$, la Corte IDH dispuso: «En cuanto al principio de favorabilidad de una ley anterior debe procurarse su armonización con el principio de proporcionalidad de manera que no se haga ilusoria la justicia penal. Todos los elementos que incidan en la efectividad de la pena deben responder a un objetivo claramente verificable y ser compatibles con la convención ${ }^{38}$. De lo que se desprende que la aplicación de la ley penal más benigna — principio de favorabilidad — no puede escindirse jamás del principio de proporcionalidad. De modo que al beneficiar a un condenado por delitos de lesa humanidad se produciría una desvirtuación de la gravedad del delito al considerar a los delitos violatorios de derechos humanos como si fuesen crímenes comunes. Aquí es importante mencionar que la CSJN incumple el art. 7.1 de la Convención Internacional para la Protección de todas las Personas contra las Desapariciones Forzadas (en adelante, CIPPDF), aprobada por Argentina según Ley 26.29839, sancionada el 14 de noviembre de 2007: «Los Estados partes considerarán el delito de desaparición forzada punible con penas apropiadas que tengan en cuenta su extrema gravedad» ${ }^{40}$. Asimismo, en el art. $5 .^{\circ}$

38 Corte Interamericana de Derechos Humanos, «Caso de la Masacre de La Rochela vs. Colombia», Sentencia de 11 de mayo de 2007, disponible en http://www.corteidh.or.cr y http://www.corteidh.or.cr/docs/casos/articulos/seriec_163_esp.pdf (consulta: 21 de septiembre de 2017).

39 Congreso de la Nación, Ley 26.298, Buenos Aires, 14 de noviembre de 2007, disponible en http://servicios.infoleg.gob.ar/infolegInternet/anexos/130000-134999/134990/ norma.htm (consulta: 21 de septiembre de 2017).

${ }^{40}$ Convención Internacional para la Protección de todas las Personas contra las Desapariciones Forzadas, París, Francia, 20 de diciembre de 2006, disponible en bttp://www.ohchr. org/SP/ProfessionalInterest/Pages/ConventionCED.aspx (consulta: 21 de septiembre de 2017). 
de la CIPPDF se puntualiza que «la práctica generalizada o sistemática de la desaparición forzada constituye un crimen de lesa humanidad $»^{40}$. Idéntica afirmación se observa en el preámbulo ${ }^{41}$ de la Convención Interamericana sobre Desaparición Forzada de Personas (en adelante, CIDFP) aprobada por la OEA en 1994 y que, asimismo, goza de jerarquía constitucional dentro del plexo normativo argentino por Ley $24.820^{42}$.

Por otro lado, debe considerarse que el beneficio concedido por la CSJN mediante la Ley 24.390 incurriría en una virtual concesión de indulto o conmutación de pena, toda vez que la decisión aporta un beneficio al condenado por delitos de lesa humanidad, supuesto que se halla prohibido por la jurisprudencia de la Corte IDH. Tal es lo que se estableció en el caso Barrios Altos vs. Perú ${ }^{43}$, en su Sentencia de 14 de marzo de 2001: «Son inadmisibles las disposiciones de amnistía, las disposiciones de prescripción y el establecimiento de excluyentes de responsabilidad que pretendan impedir la investigación y sanción de los responsables de las violaciones graves de los derechos humanos tales como la tortura, las ejecuciones sumarias, extralegales o arbitrarias y las desapariciones forzadas» ${ }^{43}$. En la misma línea, en el caso de los Hermanos Gómez Paquiyauri vs. Perú ${ }^{44}$, Sentencia de 8 de julio de 2004, la Corte IDH declaró: «El Estado deberá abstenerse de recurrir a figuras como la amnistía, la prescripción y el establecimiento de excluyentes de responsabilidad, así como medidas que pretendan impedir la persecución penal o suprimir los efectos de la sentencia condenatoria» ${ }^{44}$. Particularmente revelador resulta este último supuesto, ya que la CSJN, al aplicar la Ley 24.390, suprime de un modo evidente los efectos de la sentencia condenatoria dispuesta por la Cámara Federal de Casación Penal, morigerando la pena a delitos de lesa humanidad.

${ }^{41}$ Convención Interamericana sobre Desaparición Forzada de Personas, Belém do Pará, Brasil, 9 de junio de 1994, disponible en https://www.oas.org/juridico/spanish/ tratados/a-60.html (consulta: 21 de septiembre de 2017).

${ }^{42}$ Congreso de la Nación, Ley 24.820, Buenos Aires, 30 de abril de 1997, disponible en bttp://servicios.infoleg.gob.ar/infolegInternet/anexos/40000-44999/43555/norma.htm (consulta: 21 de septiembre de 2017).

${ }_{43}$ Corte Interamericana de Derechos Humanos, «Caso Barrios Altos vs. Perui», Sentencia de 14 de marzo de 2001, disponible en http://www.corteidh.or.cr y bttp://www.corteidh. or.cr/docs/casos/articulos/Seriec_75_esp.pdf (consulta: 21 de septiembre de 2017).

${ }^{44}$ Corte Interamericana de Derechos Humanos, «Caso de los Hermanos Gómez Paquiyauiri vs. Perú», Sentencia de 8 de julio de 2004, disponible en http://www.corteidh.or.cr y bttp://www.corteidh.or.cr/docs/casos/articulos/seriec_110_esp.pdf (consulta: 21 de septiembre de 2017). 


\section{CONCLUSIÓN}

En función de lo analizado se concluye que, efectivamente, la CSJN en el fallo Bignone, Reynaldo Benito Antonio y otro vs. recurso extraordinario incumplió la normativa interna e internacional en materia de delitos de lesa humanidad. Primeramente se efectuó una distorsión del objetivo de la Ley 24.390, ya que la misma no pudo ser concebida para beneficiar a condenados por crímenes de lesa humanidad porque en el ámbito temporal en el que se dictó (1994) no existía persecución penal contra ese tipo de delitos en Argentina en virtud de las Leyes de Obediencia Debida y Punto Final, y los indultos del presidente Menem. El auténtico fin de la Ley 24.390 fue tornar operativo el art. 7.5 CADH para cumplir con el derecho a ser juzgado dentro de un plazo razonable y reducir de este modo las dilaciones judiciales encarnadas en una prisión preventiva que se extendía en el tiempo. Sin embargo, los objetivos no se cumplieron, puesto que la ley del dos por uno acabó beneficiando a los delincuentes, debido a que el cómputo les acortaba la pena dañando severamente la finalidad por la cual fueron impuestas. De este modo, ante el alto grado de reincidencia, el Congreso Nacional dictaminó su derogación.

La CSJN aplicó una ley derogada, en clara contradicción con la voluntad del legislador, incurriendo en una aplicación completamente anacrónica del Derecho. Además, se violó la Ley 27.156 que dictamina, expresamente, la prohibición de conmutar penas en las condenas por crímenes de lesa humanidad. El beneficio de la Ley 24.390 afecta sensiblemente la antedicha disposición, ya que con su aplicación el condenado cumpliría dos días de condena por uno de prisión preventiva, obteniendo una evidente morigeración de la pena. Tal como se desprende del fallo de primera instancia Bignone, Reynaldo Benito Antonio; Muiña, Luis, y Mariani, Hipólito Rafael, del Tribunal Oral en lo Criminal núm. 2 y del fallo de la Cámara Federal de Casación Penal sobre los mismos autos, los delitos cometidos por Luis Muiña fueron calificados como crímenes de lesa humanidad. La desaparición forzada de personas que perpetró Muiña como parte activa del aparato estatal represivo de la última dictadura cívico-militar argentina en perjuicio de sus víctimas, entre las que figura Roitman — quien continua desaparecido-- configura un delito continuado o permanente mientras no se establezca el destino o paradero de la víctima. Así lo dispone el art. $3 .{ }^{\circ} \mathrm{CIDFP}^{45}$.

\footnotetext{
${ }^{45}$ Art. 3. ${ }^{\circ}$ de la Convención Interamericana sobre Desaparición Forzada de Personas:
} 
Por otro lado, el fallo de la CSJN desconoce la jurisprudencia de la Corte IDH establecida en los casos Masacre de La Rochela vs. Colombia, Barrios Altos vs. Perú y Hermanos Gómez Paquiyauri vs. Perú. En todos ellos se afirmó que: «El Estado tiene el deber ineludible de reparar de forma directa y principal aquellas violaciones de derechos humanos de las cuales es responsable, según los estándares de atribución de responsabilidad internacional y de reparación establecidos en la jurisprudencia de esta Corte» ${ }^{38}$.

Continuando con el paradigma internacional, el fallo de la CSJN vulnera la obligación de imponer sanciones adecuadas al aplicar la Ley 24.390 - concebida para delitos comunes - a delitos de lesa humanidad. Se viola el art. 7.1 y 5. ${ }^{\circ}$ CIPPDF, dado que la desaparición forzada de personas integra uno de los delitos atribuidos a Muiña; se viola el art. 6. ${ }^{\circ}$, segundo párrafo, de la Convención Interamericana para Prevenir y Sancionar la Tortura $^{46}$ —otro de los delitos por los que se halló culpable a Muiña-, ya que dicho instrumento internacional fue aprobado por Argentina el 20 de octubre de 1988 mediante Ley $23.652^{47}$, y se incumple, además, el art. 4.2 de la Convención contra la Tortura y otros Tratos o Penas Crueles, Inhumanos o Degradantes ${ }^{48}$. El fallo de la CSJN quebranta el principio de proporcionalidad de la sanción, ya que no contempló la gravedad del delito cometido por Luis Muiña. Aquí la aplicación de la Ley 24.390 resulta desproporcionada, toda vez que no fue pensada para delitos de lesa humanidad, sino para crímenes comunes, violando el estándar internacional impuesto por la Corte IDH en el caso García Ibarra y otros vs. Ecuador: «Una calificación jurídica inadecuada y una pena desproporcionada al hecho denunciado pueden ser factores de impunidad» ${ }^{49}$.

«Dicho delito será considerado como continuado o permanente mientras no se establezca el destino o paradero de la víctima».

${ }^{46}$ Art. 6. ${ }^{\circ}$, segundo párrafo, de la Convención Interamericana para Prevenir y Sancionar la Tortura: «Los Estados partes se asegurarán de que todos los actos de tortura y los intentos de cometer tales actos constituyan delitos conforme a su Derecho penal, estableciendo para castigarlos sanciones severas que tengan en cuenta su gravedad». Vid. bttp:// www.oas.org/juridico/spanish/tratados/a-51.html (consulta: 21 de septiembre de 2017).

${ }^{47}$ Congreso de la Nación, Ley 23.652, Buenos Aires, 20 de octubre de 1988, disponible en http://servicios.infoleg.gob.ar/infolegInternet/anexos/0-4999/51/norma.htm (consulta: 21 de septiembre de 2017).

48 Art. 4.2 de la Convención contra la Tortura y otros Tratos o Penas Crueles, Inhumanos o Degradantes: «Todo Estado Parte castigará esos delitos con penas adecuadas en las que se tenga en cuenta su gravedad». Vid. http://www.ohchr.org/SP/ProfessionalInterest/ Pages/CAT.aspx (consulta: 21 de septiembre de 2017).

49 Corte Interamericana de Derechos Humanos, «Caso García Ibarra y otros vs. Ecuador», Sentencia de 17 de noviembre de 2015, disponible en http://www.corteidh.or.cr y http://www. corteidh.or.cr/docs/casos/articulos/seriec_306_esp.pdf (consulta: 21 de septiembre de 2017). 
En conclusión, el fallo Bignone, Reynaldo Benito Antonio y otro vs. recurso extraordinario representa un claro retroceso en materia de derechos humanos en Argentina, en el cual la CSJN, al llevar a cabo una interpretación literal y normativista de la Ley 24.390 por medio de la aplicación de la ley penal más benigna, no sólo incumple con la legislación nacional y con las obligaciones internacionalmente asumidas por el Estado argentino, sino que establece un precedente para que otros condenados por delitos de lesa humanidad soliciten el beneficio.

\section{BIBLIOGRAFÍA}

Agencia TéLAm, «Diputados aprobó el proyecto para bloquear cualquier reducción de penas a genocidas», 2017, disponible en http://www.telam.com.ar/ notas/201705/188390-diputados-aprueba-debatir-un-proyecto-contra-el-2x1.btml (consulta: 21 de septiembre de 2017).

BraslavsKy, G., «Masiva marcha a Plaza de Mayo en repudio del fallo del 2x1 para los represores», Diario Clarín, 2017, disponible en https://www.clarin.com/politicalmasiva-marcha-plaza-mayo-repudiar-fallo-represores_0_rkTThNWeW.btml (consulta: 18 de septiembre de 2017).

Cámara de Diputados de la Provincia de Buenos Aires, Ley 14.910, Provincia de Buenos Aires, 12 de mayo de 2017, disponible en https://www.hcdiputados-ba.gov.ar/includes/ley_completa.php?vnroley=14910 (consulta: 18 de septiembre de 2017).

Cámara Federal de Casación Penal, Sala IV, «Bignone, Reynaldo Benito A. y otro vs. recurso de casación», Sentencia de 28 de marzo de 2014, causa núm. 1731/2013, disponible en bttp://www.fiscales.gob.ar/ y bttp://www.fiscales.gob.ar/wp-content/uploads/2014/05/fallo-casaci\%C3\%B3n-2x1-BignoneMui\%C3\%B1a.pdf (consulta: 18 de septiembre de 2017).

Clariá Olmedo, J., Derecho Procesal Penal, t. I, Córdoba, Rubinzal-Culzoni, 1984, pp. 104-105.

Código Penal de la Nación Argentina, Ley 11.179, disponible en http://servicios.infoleg.gob.ar/infolegInternet/anexos/15000-19999/16546/texact.htm\#2 (consulta: 19 de septiembre de 2017).

COMIIIÓN INTERAMERICANA DE DereCHOS HuMANOS, Comunicado de prensanúm. 060/17, 15 de mayo de 2017, Washington DC, disponible en http://www.oas.org/ es/cidh/prensa/comunicados/2017/060.asp (consulta: 18 de septiembre de 2017).

Congreso de la Nación, Ley 23.054, Buenos Aires, 19 de mayo de 1984, disponible en http://servicios.infoleg.gob.ar/infolegInternet/anexos/25000-29999/28152/ norma.htm (consulta: 19 de septiembre de 2017).

- Ley 23.313, Buenos Aires, 6 de mayo de 1986, disponible en http://servicios. infoleg.gob.ar/infolegInternet/anexos/20000-24999/23782/norma.htm (consulta: 19 de septiembre de 2017). 
- Ley 23.492, Buenos Aires, 24 de diciembre de 1986, disponible en bttp:// servicios.infoleg.gob.ar/infolegInternet/anexos/20000-24999/21864/norma.btm (consulta: 21 de septiembre de 2017).

- Ley 23.652, Buenos Aires, 20 de octubre de 1988, disponible en bttp://servicios.infoleg.gob.ar/infolegInternet/anexos/0-4999/51/norma.htm (consulta: 21 de septiembre de 2017).

- Ley 24.390, Buenos Aires, 21 de noviembre de 1994, disponible en bttp://servicios.infoleg.gob.ar/infolegInternet/anexos/0-4999/776/norma.btm (consulta: 18 de septiembre de 2017).

- Ley 24.820, Buenos Aires, 30 de abril de 1997, disponible en bttp://servicios. infoleg.gob.ar/infolegInternet/anexos/40000-44999/43555/norma.htm (consulta: 21 de septiembre de 2017).

- Ley 25.430, Buenos Aires, 30 de mayo de 2001, disponible en bttp://servicios. infoleg.gob.ar/infolegInternet/anexos/65000-69999/67171/norma.htm (consulta: 18 de septiembre de 2017).

- Ley 26.200, Buenos Aires, 5 de enero de 2007, disponible en bttp://servicios.infoleg.gob.ar/infolegInternet/anexos/120000-124999/123921/norma.btm (consulta: 19 de septiembre de 2017).

- Ley 26.298, Buenos Aires, 14 de noviembre de 2007, disponible en bttp://servicios.infoleg.gob.ar/infolegInternet/anexos/130000-134999/134990/norma.htm (consulta: 21 de septiembre de 2017).

- Ley 27.156, Buenos Aires, 24 de julio de 2015, disponible en bttp://servicios.infoleg.gob.ar/infolegInternet/anexos/245000-249999/249820/norma.btm (consulta: 21 de septiembre de 2017).

- Ley 27.362, Buenos Aires, 10 de mayo de 2017, disponible en http://servicios.infoleg.gob.ar/infolegInternet/anexos/270000-274999/274607/norma.htm (consulta: 18 de septiembre de 2017).

Constitución de la Nación Argentina, Buenos Aires, Editorial del Ministerio de Justicia y Derechos Humanos de la Nación, 1994, disponible en bttp://servicios.infoleg.gob.ar/infolegInternet/anexos/0-4999/804/norma.btm (consulta: 19 de septiembre de 2017).

Convención Americana sobre Derechos Humanos (Pacto de San José), San José, Costa Rica, 22 de noviembre de 1969, disponible en https://www.oas.org/dil/ esp/tratados_b-32_convencion_americana_sobre_derechos_bumanos.btm (consulta: 19 de septiembre de 2017).

Convención contra la Tortura y Otros Tratos o Penas Crueles, Inhumanos o Degradantes, Nueva York, 10 de diciembre de 1984, disponible en bttp:// www.ohchr.org/SP/ProfessionalInterest/Pages/CAT.aspx (consulta: 21 de septiembre de 2017).

Convención Interamericana para Prevenir y Sancionar la Tortura, Cartagena de Indias, Colombia, 9 de diciembre de 1985, disponible en bttp://www.oas. org/juridico/spanish/tratados/a-51.html (consulta: 21 de septiembre de 2017). 
Convención Interamericana sobre Desaparición Forzada de Personas, Belém do Pará, Brasil, 9 de junio de 1994, disponible en https://www.oas.org/juridico/ spanish/tratados/a-60.html (consulta: 21 de septiembre de 2017).

Convención Internacional para la Protección de todas las Personas contra las Desapariciones Forzadas, París, Francia, 20 de diciembre de 2006, disponible en bttp://www.obchr.org/SP/Professionalinterest/Pages/ConventionCED. aspx (consulta: 21 de septiembre de 2017).

Corte Interamericana de Derechos Humanos, «Caso Barrios Altos vs. Perú», Sentencia de 14 de marzo de 2001, disponible en bttp://www.corteidh.or.cr y bttp://www.corteidh.or.cr/docs/casos/articulos/Seriec_75_esp.pdf (consulta: 21 de septiembre de 2017).

- «Caso de los Hermanos Gómez Paquiyauiri vs. Perú», Sentencia de 8 de julio de 2004, disponible en http://www.corteidh.or.cr y http://www.corteidh.or.cr/ docs/casos/articulos/seriec_110_esp.pdf(consulta: 21 de septiembre de 2017).

- «Caso de la Masacre de La Rochela vs. Colombia», Sentencia de 11 de mayo de 2007, disponible en http://www.corteidh.or.cr y http://www.corteidh.or.cr/ docs/casos/articulos/seriec_163_esp.pdf (consulta: 21 de septiembre de 2017).

- «Caso García Ibarra y otros vs. Ecuador», Sentencia de 17 de noviembre de 2015, disponible en http://www.corteidh.or.cr y http://www.corteidh.or.cr/ docs/casos/articulos/seriec_306_esp.pdf (consulta: 21 de septiembre de 2017).

Corte Suprema de Justicia de la Nación Argentina, Vigil, Constancio y otros vs. contrabando, Sentencia de 9 de noviembre de 2000, fallos 323:3426, disponible en bttp://www.csjn.gov.ar y bttp://sjconsulta.csin.gov.ar/sjconsulta/documentos/verUnicoDocumentoLink. html? idAnalisis $=494138$ Ecache $=1505940475397$ (consulta: 20 de septiembre de 2017).

- Bignone, Reynaldo Benito Antonio y otro vs. recurso extraordinario, Sentencia de 3 de mayo de 2017, fallos 340:549, disponible en bttp://www.csjn.gov.ar y bttp://sjconsulta.csin.gov.ar/sjconsulta/documentos/verDocumentoByIdLinksJSP.html?idDocumento=7373073 (consulta: 18 de septiembre de 2017).

Diario La Nación, «El Senado votó por unanimidad y es ley el límite al "dos por uno"», La Nación, 2017, disponible en bttp://www.lanacion.com.ar/2022574el-senado-voto-por-unanimidad-y-es-ley-el-limite-al-dos-por-uno (consulta: 21 de septiembre de 2017).

Diario de Sesiones de la Convención Nacional Constituyente, 35. " reunión, 3. a sesión ordinaria (continuación), 22 de agosto de 1994, disponible en bttp://www1. bcdn.gov.ar/dependencias/dip/Debate-constituyente.htm (consulta: 21 de septiembre de 2017).

Estatuto de Roma de la Corte Penal Internacional, Roma, Italia, 17 de julio de 1998, disponible en http://www.acnur.org/fileadmin/scripts/doc.php?file= fileadmin/Documentos/BDL/2002/0033 (consulta: 19 de septiembre de 2017).

Mignone, F., «Los decretos de indulto en la República Argentina», Revista IIDH, núm. 12 (1990), pp. 259-278, disponible en bttp://www.iidh.ed.cr/IIDH/ media/1615/revista-iidb12.pdf (consulta: 21 de septiembre de 2017). 
Ministerio de Justicia y Derechos Humanos de la Nación Argentina, Registro Unificado del Terrorismo de Estado (RUVTE), «Listado de víctimas del accionar represivo ilegal», 30 de septiembre de 2016, disponible en bttp:// datos.jus.gob.ar/dataset/registro-unificado-de-victimas-del-terrorismo-de-estadoruvte (consulta: 18 de septiembre de 2017).

Moreiro, L., «Proponen derogar el beneficio del 2x1», La Nación, 2000, disponible en bttp://www.lanacion.com.ar/22963-proponen-derogar-el-beneficio-del2- $x$-1 (consulta: 21 de septiembre de 2017).

Organización de Naciones Unidas (ONU), Oficina del Alto Comisionado para los Derechos Humanos (ACNUDH), Comunicado oficial, 17 de junio de 2017, Ginebra, Suiza, disponible en bttp://www.ohchr.org/Documents/Issues/ Truth/ComunicacionConjuntafromSP_Ley2x1Argentina.pdf (consulta: 18 de septiembre de 2017).

Pacto Internacional de Derechos Civiles y Políticos, Nueva York, 16 de diciembre de 1966, disponible en http://www.ohchr.org/SP/ProfessionalInterest/Pages/CCPR.aspx (consulta: 19 de septiembre de 2017).

Poder Ejecutivo Nacional, Decreto 329/2017, Buenos Aires, 11 de mayo de 2017, disponible en http://servicios.infoleg.gob.ar/infolegInternet/anexos/270000-274999/274608/norma.htm (consulta: 18 de septiembre de 2017).

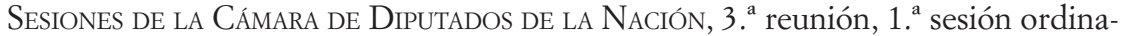
ria, 14 de marzo de 2001, disponible en http://www1.hcdn.gov.ar/sesionesxml/ reunion.asp? $p=119 \varepsilon r=3$ (consulta: 21 de septiembre de 2017).

- 6. ${ }^{a}$ reunión, 4. ${ }^{a}$ sesión ordinaria (especial), 9 de mayo de 2017, disponible en bttp://www.diputados.gov.ar/ (consulta: 21 de septiembre de 2017).

Sesiones de la Cámara de Senadores de la Nación, 24. ${ }^{a}$ reunión, 6. ${ }^{a}$ sesión ordinaria, 3 de mayo de 2001, disponible en http://www.senado.gob.ar/ y bttp:// www.senado.gob.ar/parlamentario/sesiones/busqueda (consulta: 21 de septiembre de 2017).

- 6. ${ }^{a}$ reunión, $4 .^{a}$ sesión especial, 10 de mayo de 2017, disponible en bttp://www. senado.gov.ar/ (consulta: 21 de septiembre de 2017).

Tribunal Oral en lo Criminal Federal, núm. 2, «Bignone, Reynaldo Benito Antonio; Muiña, Luis, y Mariani, Hipólito Rafael s/inf. arts. 144 bis, inciso 1. ${ }^{\circ}$ y último párrafo - Ley 14.616-; 142, incisos $1 .^{\circ}$ y 5. ${ }^{\circ}$ - Ley 20.642- del CP», Sentencia del 29 de diciembre de 2011, causa núm. 1696, disponible en http://www.cij.gov.ar/ y http://www.cij.gov.ar/nota-8497-Derechos-humanos-condenaron-a-Bignone-a-15-anos-de-prision-por-crimenescometidos-en-el-Hospital-Posadas.btml (consulta: 18 de septiembre de 2017). 